\title{
ELECTROCHEMICAL DECOLORIZATION AND REMOVAL OF INDIGO CARMINE TEXTILE DYE FROM WASTEWATER
}

\author{
STERGIOPOULOS D. ${ }^{1}$ \\ DERMENTZIS K. ${ }^{1}$ \\ GIANNAKOUDAKIS P. ${ }^{2}$ \\ SOTIROPOULOS S. ${ }^{2}$
}

Received: $14 / 01 / 2014$

Accepted: 11/03/2014

Available online: $21 / 03 / 2014$

\author{
${ }^{1}$ Department of Petroleum \& Natural Gas Technology \\ Kavala Institute of Technology \\ Agios Loukas, 65404, Kavala, Greece \\ ${ }^{2}$ Department of Chemistry \\ Aristotle University of Thessaloniki \\ 54124, Thessaloniki, Greece
}

*to whom all correspondence should be addressed: e-mail: dstergio@gmail.com

\section{ABSTRACT}

The present paper discusses an integrated electrochemical decolorization/degradation treatment procedure of indigo carmine dye, which comprises electrocoagulation, electrooxidation and advanced electrochemical oxidation using the electro-Fenton process.

The electrocoagulation process is performed by sacrificial iron electrodes, the indirect electrooxidation process by dimensionally stable $\mathrm{Ti} / \mathrm{Pt}$ and graphite electrodes in $\mathrm{NaCl}$ electrolyte solution, and the electro-Fenton process by iron electrodes and added amounts of $\mathrm{H}_{2} \mathrm{O}_{2}$. All electrochemical experiments are conducted in the same electrochemical cell with the same apparent electrode surface and interelectrode distance.

The three different electrochemical processes are discussed, their efficiencies compared and evaluated. The initial dye concentration of $100 \mathrm{mg} \mathrm{l}^{-1}$ was fast and efficiently removed in only a few minutes of electroprocessing time. The electro-Fenton treatment is the fastest, most efficient and economical process operated at very low current densities of 0.33 and $0.66 \mathrm{~mA} \mathrm{~cm}^{-2}$ and consuming only $4.75 \times 10^{-3}$ and $5.23 \times 10^{-3} \mathrm{kWh} \mathrm{m}^{-3}$ of treated solution respectively. The electrocoagulation treatment with iron electrodes and the electrooxidation process with $\mathrm{Ti} / \mathrm{Pt}$ electrodes conducted at applied current densities of $5 \mathrm{~mA} \mathrm{~cm} \mathrm{~m}^{-2}$ consumed 0.511 and $0.825 \mathrm{kWh} \mathrm{m}^{-3}$ of treated solution respectively. The proposed procedure is a safe, economical and efficient method for removal of indigo carmine dye from aqueous solutions and dye house effluents.

Keywords: Dye house effluents, electrochemical coagulation, anodic oxidation, electro-Fenton, wastewater remediation.

\section{Introduction}

The textile industry consumes enormous amounts of water during dyeing and finishing operations. Typical medium-scale textile factories produce approximately $1000 \mathrm{~m}^{3}$ of wastewater per day. It is estimated that around $30 \%$ of the applied dyes remain unfixed and are discharged in the effluent. Dye bearing wastewaters are toxic for the environment since dyes are stable compounds and may cause carcinogenesis. Conventional biological treatment processes are often less successful because most dyes are barely or non biodegradable (Beydili et al., 2001; Aygün et al., 2012). 
Indigo Carmine (5.5'-indigo disulfonic acid disodium salt) is a dark blue dye mainly used in the textile industry for the dyeing of polyester fibers and denim (blue jeans) (Secula et al., 2011). Indigo Carmine is also used as dye in food and cosmetics industry. Several processes have been suggested for removal of Indigo Carmine and other dyes from wastewater including adsorption (Kyzas et al., 2012), photochemical (Caliman et al., 2007) and electrochemical methods (Ammar et al., 2006; Flox et al., 2006; Secula et al., 2011; Dogan \& Turkdemir, 2012; Hammami et al., 2012).

Dogan \& Türkdemir, 2005, reported an almost 100\% removal of color and $60 \%$ of COD from an $0.1 \mathrm{w} / \mathrm{v}$ aqueous indigo carmine solution in $90 \mathrm{~min}$. residence time by the electrooxidation process with platinum electrodes. Secula et al., 2011, achieved almost 99\% removal of indigo carmine from an aqueous solution containing $40 \mathrm{mg} \mathrm{l}^{-1}$ dye by the electrocoagulation process with steel electrodes, at a current density of $10.91 \mathrm{~A} \mathrm{~m}^{-2}$ and a residence time of $180 \mathrm{~min}$. Ammar et al. (2006), studied the electrochemical oxidation of indigo carmine at boron-doped diamond anode, whereas Flox et al. (2006), and Hammami et al. (2012), worked on electro-Fenton degradation of the dye and obtained similar results. As far as we are aware, no other paper has appeared in literature up to now presenting a combination and comparative study of all three electrochemical processes i.e. the electrocoagulation, electrooxidation and electro-Fenton processes.

Electrochemical processes for pollution abatement have been proved viable alternatives or complementary to biological treatment in some instances, especially when pollutants are recalcitrant to biological processing. They are based mainly on direct anodic oxidation at dimensionally stable electrodes (Vlyssides et al., 1999; Chatzisymeon et al., 2006; Motoc et al., 2012), advanced electrochemical oxidation (Oturan and Brillas, 2007; El-Desoky et al., 2010; Wang et al., 2010) and electrocoagulation with sacrificial aluminium or iron electrodes (Kabdasli et al., 2009; Körbahti et al., 2011; Dermentzis et al., 2011a; Dermentzis et al., 2011b). The advantages of electrochemical treatment are various and well documented: the catalyst/electrode is immobilized i.e. without the need to separate the catalyst from the reaction mixture, the variables such as current and potential are easily controlled facilitating automation of the process.

The present paper discusses an integrated electrochemical decolorization/degradation treatment of the Indigo Carmine dye, which comprises electrocoagulation with iron sacrificial electrodes, indirect anodic oxidation at dimensionally stable $\mathrm{Ti} / \mathrm{Pt}$ and graphite anodes in $\mathrm{NaCl}$ electrolyte solution and advanced electrochemical oxidation using the electro-Fenton process with iron sacrificial anode and added amount of hydrogen peroxide. The efficiencies of the three different electrochemical processes are compared and evaluated.

\section{Methods}

\subsection{Chemicals}

$\mathrm{NaCl}, \mathrm{NaOH}$ and $\mathrm{H}_{2} \mathrm{O}_{2}$ were of analytical grade (Merck). $\mathrm{pH}$ was adjusted with $0.1 \mathrm{~mol} \mathrm{I}^{-1}$ solutions of $\mathrm{H}_{2} \mathrm{SO}_{4}$ and $\mathrm{NaOH}$ as required. The reactive dye indigo carmine (Disodium (2E)-3-oxo-2-(3-oxo-5sulfonato-1,3-dihydro-2H-indol-2-ylidene)-5-indoline-sulfonate) was purchased from Aldrich (CAS Nr: 860-22-0). Its structure is shown in Figure 1.

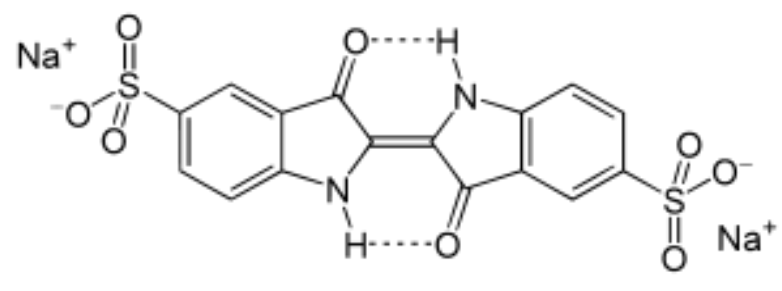

Figure 1. Chemical structure of reactive dye indigo carmine Mr: 466.36,Linear Formula: $\mathrm{C}_{16} \mathrm{H}_{8} \mathrm{~N}_{2} \mathrm{O}_{8} \mathrm{~S}_{2} \mathrm{Na}_{2}$ ) 


\subsection{Apparatus}

A laboratory model DC power supply apparatus (STELL TRAFO, PHYWE Systeme GmbH \& Co. KG Germany) was used to maintain constant DC current. Voltage and current were measured by a multimeter (PHYWE). Conductivity was measured by means of a conductometer (inoLab Cond. Level 1, WTW). $\mathrm{pH}$ was measured by a WTW pH-meter. Electrolyses were conducted at room temperature in a cylindrical glass cell of $500 \mathrm{ml}$. The treated solution of $250 \mathrm{ml}$ was rigorously stirred with a magnetic bar at $500 \mathrm{rpm}$. The electrodes for the electrooxidation experiments were two platinized titanium plates $(\mathrm{Ti} / \mathrm{Pt})$ and two graphite plate electrodes, while for electrocoagulation and electro-Fenton two iron plates (obtained commercially) were used with an apparent area of $30 \mathrm{~cm}^{2}$ each.

\subsection{Analytical Procedures}

UV-VIS Spectrophotometry (HITACHI U-2000, Japan) was used for spectrographic analysis of dye concentrations. Known concentrations of the indigo carmine dye solution were scanned at optimum absorption wavelength of $612 \mathrm{~nm}$ wavelength for generating the calibration plot. Samples were diluted using distilled water if the absorbance exceeded the range of calibration curve. All samples were filtered using polytetrafluorethylene filters with a pore size of $0.45 \mu \mathrm{m}$ (Whatman).

\subsection{Experimental Procedures}

All electrochemical experiments: electrocoagulation, electrooxidation and electro-Fenton were conducted in the $500 \mathrm{ml}$ electrochemical reactor. The inter-electrode distance was $0.5 \mathrm{~cm} . \mathrm{H}_{2} \mathrm{O}_{2}$ was added to the reactor during the electro-Fenton treatment. The concentration of $\mathrm{NaCl}$ was $6 \mathrm{~g} \mathrm{l}^{-1}$. The applied current densities were 5 and $10 \mathrm{~mA} \mathrm{~cm}^{-2}$ for electrocoagulation, $5 \mathrm{~mA} \mathrm{~cm}$ for electro-oxidation, while only 0.33 and $0.66 \mathrm{~mA} \mathrm{~cm}$ for electro-Fenton was used. $\mathrm{pH}$ was adjusted to 6.9 for electrocoagulation and to 3 for electro-Fenton and electrooxidation experiments respectively.

\subsection{Brief description of electrochemical processes}

\subsubsection{Electrocoagulation}

Electrocoagulation is a process consisting of creating metallic hydroxide flocks inside the wastewater by electrodissolution of soluble anodes made of iron or aluminum. The main reactions occurring during iron electrocoagulation produce ferrous and ferric ions at the sacrificial anode and hydroxide ions as well hydrogen gas at the cathode:

$$
\begin{array}{lc}
\mathrm{Fe} \rightarrow \mathrm{Fe}^{2+}+2 \mathrm{e}^{-} & \text {(anode) } \\
\mathrm{Fe} \rightarrow \mathrm{Fe}^{3+}+3 \mathrm{e}^{-} & \text {(anode) } \\
2 \mathrm{H}_{2} \mathrm{O}+2 \mathrm{e}^{-} \rightarrow 2 \mathrm{OH}^{-}+\mathrm{H}_{2} & \text { (cathode) }
\end{array}
$$

The generated $\mathrm{Fe}^{2+}, \mathrm{Fe}^{3+}$ and $\mathrm{OH}^{-}$ions react to form various monomeric and polymeric species which finally result in situ formation of gelatinous $\mathrm{Fe}(\mathrm{OH})_{2}$ and $\mathrm{Fe}(\mathrm{OH})_{3}$ effecting the coagulation and coprecipitation or $\mathrm{H}_{2}$ flotation of particulates from the solution by adsorption.

\subsubsection{Anodic oxidation}

Organic matter can be anodically destroyed in two different mechanisms, namely: direct oxidation, where the pollutants are adsorbed on the anode surface and destroyed by the electron transfer reaction and (b) indirect oxidation in the liquid bulk by the electrochemically mediated oxidants, such as chlorine, hypochlorite, hydroxyl radicals, ozone and hydrogen peroxide. In anodic oxidation organic pollutants are attacked by the absorbed hydroxyl radicals formed as intermediates from water oxidation to $\mathrm{O}_{2}$ at the surface of dimensionally stable anodes (graphite, $\mathrm{Pt}, \mathrm{TiO}_{2}, \mathrm{IrO}_{2}, \mathrm{PbO}_{2}$ or boron doped diamond electrodes). 


\subsubsection{Electro-Fenton process}

Fenton's reagent is an acidic mixture of hydrogen peroxide and $\mathrm{Fe}^{2+}$, where free hydroxyl radicals with high oxidative power are produced as follows:

$\mathrm{Fe}^{2+}+\mathrm{H}_{2} \mathrm{O}_{2} \rightarrow \mathrm{Fe}^{3+}+\mathrm{OH}^{*}+\mathrm{OH}^{-}$

Recently, the Fenton's reagent has been produced in situ electrochemically (electro-Fenton) in two ways:

(a) by addition of a catalytic amount of $\mathrm{Fe}^{2+}$ ions, reduction of oxygen and regeneration of $\mathrm{Fe}^{2+}$ on a suitable cathode in acidic media:

$\mathrm{O}_{2}+2 \mathrm{H}^{+}+2 \mathrm{e}^{-} \rightarrow \mathrm{H}_{2} \mathrm{O}_{2}$

$$
\mathrm{E}^{\circ}=0.67 \mathrm{~V}
$$

$\mathrm{Fe}^{3+}+\mathrm{e}^{-} \rightarrow \mathrm{Fe}^{2+}$

$E^{\circ}=0.771 \mathrm{~V}$

and

(b) by addition of $\mathrm{H}_{2} \mathrm{O}_{2}$ and electrochemical production of $\mathrm{Fe}^{2+}$ ions with a sacrificial Fe anode according to the anodic reaction (1)

In this case, a part of $\mathrm{Fe}^{3+}$ ions is produced from Fenton's reaction (Eq.4) between supplied $\mathrm{H}_{2} \mathrm{O}_{2}$ and electroregenerated $\mathrm{Fe}^{2+}$ which precipitates as $\mathrm{Fe}(\mathrm{OH})_{3}$. Therefore, the organic pollutants can be removed by oxidation with $\mathrm{OH}^{*}$ radicals and simultaneously by electrocoagulation with the $\mathrm{Fe}(\mathrm{OH})_{3}$ precipitate (Brillas and Casado, 2002 ; Oturan and Brillas, 2007; Yatmaz and Uzman, 2009).

\section{Results}

\subsection{Removal of indigo carmine by electrocoagulation}

The decolorization of the indigo carmine wastewater was investigated by electrocoagulation using iron electrodes as anode and cathode at different current densities and $\mathrm{NaCl}\left(6 \mathrm{~g} \mathrm{I}^{-1}\right)$ as electrolyte solution. $\mathrm{pH}$ was adjusted to the optimum value of 6.9 (Mollah et al., 2009) with a dilute $\mathrm{NaOH}$ solution.

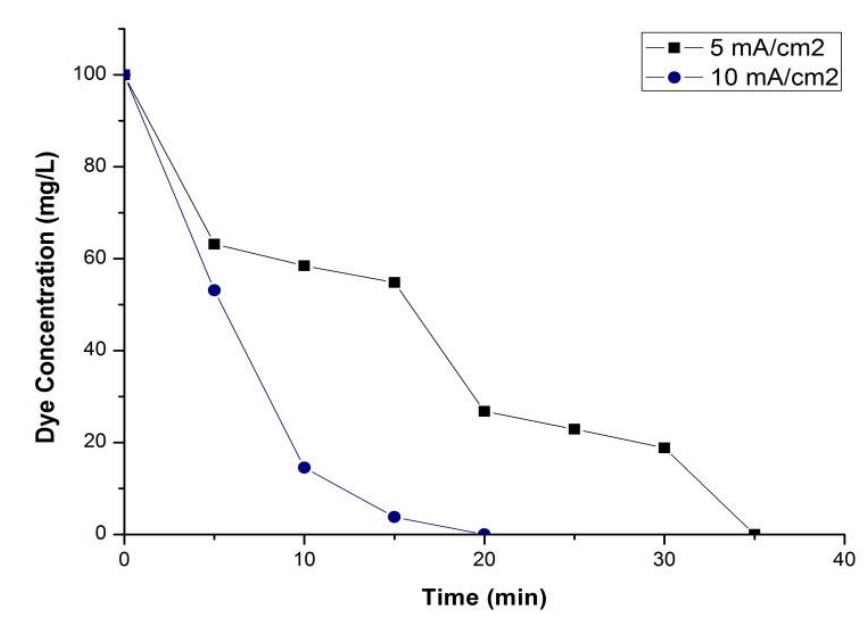

Figure 2. Effect of applied current density on residual dye concentration versus time during electrocoagulation treatment of indigo carmine

According to Figure 2, for the two current densities 5 and $10 \mathrm{~mA} \mathrm{~cm}{ }^{-2}$ the initial concentration of $100 \mathrm{mg} \mathrm{l}^{-1}$ indigo carmine fell under the detection limit $\left(0.008 \mathrm{mg} \mathrm{l}^{-1}\right)$ in 35 and 20 minutes of electrolysis 
time respectively. The removal rate is faster with increasing current density. This is a presumable phenomenon, as the current density determines the coagulant dosage rate, the bubble production and the flock size and growth (Koshla et al., 1991). The initial solution pH of 6.9 changed to 8.8, i.e. no significant $\mathrm{pH}$ change was observed during electroprocessing. During the electrocoagulation process the indigo carmine dye is not destructed. The dye molecule is absorbed and relocated as a whole in the electro-generated $\mathrm{Fe}(\mathrm{OH})_{3}$ precipitate.

The electrical energy consumptions for the two runs at the corresponding current densities of 5 and $10 \mathrm{~mA} \mathrm{~cm}{ }^{-2}$ are calculated from Eq.7:

$\mathrm{E}=\frac{\mathrm{U} \times \mathrm{I} \times \mathrm{t}}{\mathrm{V}}$

where:

$U=$ voltage (Volts), $I=$ current intensity (A), $t=$ time (s) and $V=$ solution volume of wastewater, and amount to 0.511 and $0.825 \mathrm{kWh} \mathrm{m}^{-3}$ of treated dye wastewater respectively.

\subsection{Degradation of Indigo carmine dye by electrooxidation}

The degradation of indigo carmine from aqueous solution of 100 was investigated by indirect electrooxidation at platinized titanium $(\mathrm{Ti} / \mathrm{Pt})$ and graphite electrodes as anode and cathode. $\mathrm{NaCl}$ $\left(6 \mathrm{~g} \mathrm{l}^{-1}\right)$ was used as supporting electrolyte to increase the solution conductivity and therefore reduce the resistance and the electrical energy consumption. $\mathrm{H}_{2} \mathrm{SO}_{4}$ was added to the dye solution until it reached $\mathrm{pH}=3$. As has been shown, (Chatzisymeon et al., 2006; Dogan and Turkdemir, 2012; Vlyssides et al., 1999; Yatmaz and Uzman, 2009), acidic electrolyte solutions favor the electrooxidation process by increasing the oxidation power of the oxidants $\left(\mathrm{Cl}_{2}, \mathrm{HOCl}, \mathrm{O}_{3}, \mathrm{OH}^{*}, \mathrm{H}_{2} \mathrm{O}_{2}\right)$ which are produced during the electrooxidation treatment of organic pollutants. For this reason the optimum acidic solution of $\mathrm{pH}=3$ was selected as the operation $\mathrm{pH}$. The applied current density was held at $5 \mathrm{~mA} \mathrm{~cm}^{-2}$.

According to Figure 3 the initial dye concentration of $100 \mathrm{mg} \mathrm{I}^{-1}$ was completely reduced in 20 and 35 minutes of electroprocessing using $\mathrm{Ti} / \mathrm{Pt}$ and graphite electrodes respectively. This is due to the anodic oxidation of $\mathrm{Cl}^{-}$ions and the formation of free chlorine. As known, chlorine in acidic solution is a strong oxidizing agent causing indirect oxidation of the dye in the bulk solution.

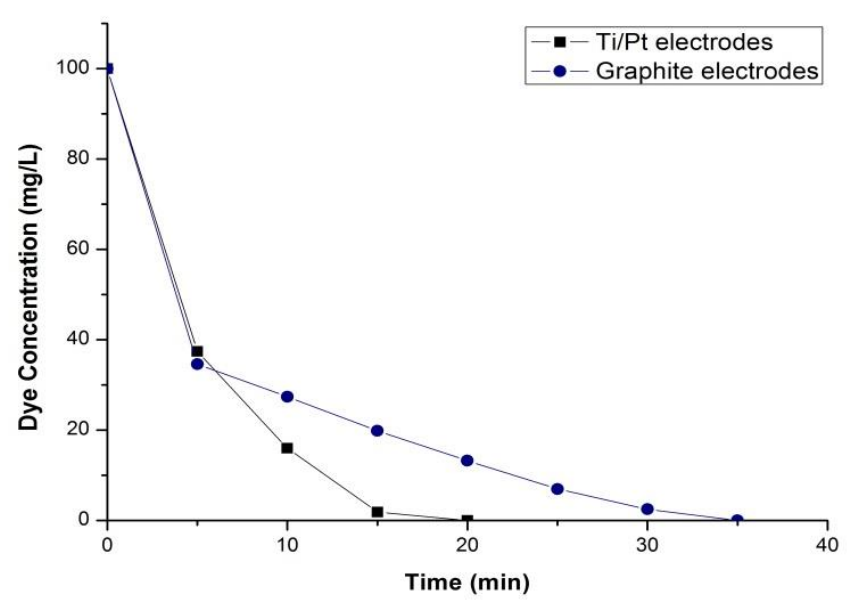

Figure 3. Residual dye concentration versus time during electrooxidation of indigo carmine in $\mathrm{NaCl}$ electrolyte at $\mathrm{Ti} / \mathrm{Pt}$ and graphite electrodes

The electrical energy consumptions calculated from Eq.8 for the electrooxidation treatment with Ti/Pt and graphite electrodes are 0.874 and $1.75 \mathrm{kWh} \mathrm{m}^{-3}$ of treated dye wastewater respectively. 


\subsection{Degradation of indigo carmine by electro-Fenton}

Fenton reagent is generally conducted in acidic solutions with $\mathrm{pH}$ values ranging from 2 to 4 with $\mathrm{pH}=3$ being the optimum. Hence, the dye solution was acidified with $\mathrm{H}_{2} \mathrm{SO}_{4}$ until it reached $\mathrm{pH}=3$. The electroFenton experiment was conducted at low applied current densities of only 0.33 and $0.66 \mathrm{~mA} \mathrm{~cm}{ }^{-2}$ with

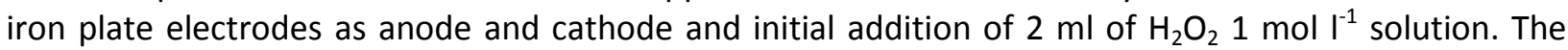
solution $\mathrm{pH}$ tending to increase slightly during the process was monitored and adjusted with a dilute $\mathrm{H}_{2} \mathrm{SO}_{4}$ solution to the optimal pH value of 3 . Figure 4 shows that the initial concentration of $100 \mathrm{mg} \mathrm{I}^{-1}$ indigo carmine dye was completely decolorized and degraded in only 1 and 2 minutes of electrolysis time at the applied current densities of 0.66 and $0.33 \mathrm{~mA} \mathrm{~cm}{ }^{-2}$ respectively. Compared to electrooxidation the electro-Fenton process is by far faster, due to the fast reaction of the indigo carmine dye and its molecule fragments with the very reactive $\mathrm{OH}^{*}$ radicals generated from corresponding reaction equation (Eq.4).

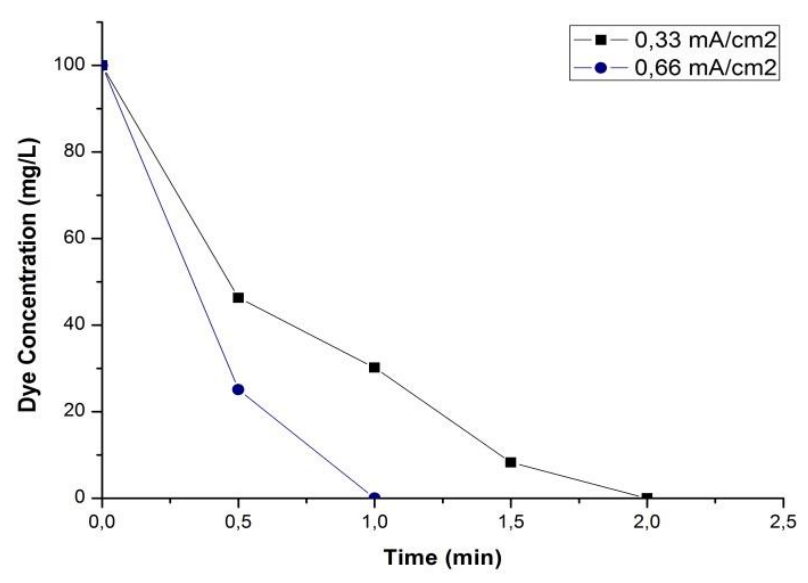

Figure 4. Residual dye concentration versus time during the electro-Fenton treatment

In addition to electro-Fenton degradation the indigo carmine dye or its molecule fragments can partially be absorbed and co-precipitate with the generated $\mathrm{Fe}(\mathrm{OH})_{3}$ flocs and therefore be removed by electrocoagulation as pointed out in section 2.5.3. However, this way of dye removal by electrocoagulation is slow because of the low solution $\mathrm{pH}$.

The electrical energy consumptions for dye degradation after 2 and 1 minutes of electrolysis time at the applied current densities of 0.33 and $0.66 \mathrm{~mA} \mathrm{~cm}^{-2}$ are $4.75 \times 10^{-3}$ and $5.23 \times 10^{-3} \mathrm{kWh} \mathrm{m}^{-3}$ of treated dye solution respectively.

\section{Conclusions}

The electrooxidation process with $\mathrm{Ti} / \mathrm{Pt}$ and graphite electrodes in the presence of $\mathrm{NaCl}$ as supporting electrolyte decolorizes indigo carmine dye due to indirect electrooxidation of the dye molecules in the bulk solution with the anodically generated chlorine. The electrical energy consumptions at the applied current density of $5 \mathrm{~mA} \mathrm{~cm}{ }^{-2}$ with Ti/Pt and graphite electrodes are 0.874 and $1.75 \mathrm{kWh} \mathrm{m}^{-3}$ of treated dye solution respectively.

The electrocoagulation process with iron electrodes is a more efficient method for decolorization of aqueous indigo carmine bearing solutions achieving 100\% color removal in 35 and 20 minutes of electroprocessing at the applied current densities of 5 and $10 \mathrm{~mA} \mathrm{~cm}^{-2}$ with the corresponding energy consumption 0.511 and $0.825 \mathrm{kWh} \mathrm{m}^{-3}$ of treated dye solution respectively. The electro-Fenton process with Fe electrodes and supplied $\mathrm{H}_{2} \mathrm{O}_{2}$ in acidic solution is the fastest and more efficient method for 
degradation of indigo carmine dyes. Applying current densities of 0.33 and $0.66 \mathrm{~mA} \mathrm{~cm}^{-2} 100 \%$ the degradation of the dye was achieved in only 2 and 1 minutes of electroprocessing. The energy consumption was $4.75 \times 10^{-3}$ and $5.23 \times 10^{-3} \mathrm{kWh} \mathrm{m}^{-3}$ of treated dye solution.

\section{References}

Ammar S., Abdelhedi R., Flox C., Arias C. and Brillas E. (2006), Electrochemical degradation of the dye indigo carmine at boron-doped diamond anode for wastewaters remediation, Environmental Chemistry Letters, 4, 229-233.

Aygün A., Yilmaz T., Nas B. and Berktay A. (2012), Effect of temperature on Fenton oxidation of young landfill leachate: kinetic assessment and sludge peoperties, Global NEST Journal, 14, 487-495.

Beydill M.I., Matthews R.D. and Pavlostathis S.G. (2001), Decolorization of a reactive copper phthalocyanine dye under methanogenic conditions, Water Science and Technology, 43, 333-340.

Brillas E. and Casado J. (2002), Aniline degradation by electro-Fenton and peroxi-coagulation processes using a flow reactor for wastewater treatment, Chemosphere, 47, 241-248.

Caliman A.F., Berberidou Ch., Lazar L., Poulios I. and Macoveanu M. (2007), Degradation of Alcian blue 8GX by heterogenous and homogenous photocatalytic processes, Environmental Engineering and Management Journal, 6, 85-93.

Chatzisymeon E., Xekoukoulotakis N.P., Coz A., Kalogerakis N. and Mantzavinos D. (2006), Electrochemical treatment of textile dyes and dyehouse effluents, Journal of Hazardous Materials, B137, 998-1007.

Dermentzis K., Marmanis D., Valsamidou E., Christoforidis A. and Ouzounis K. (2011), Electrochemical decolorization treatment of nickel phthalocyanine reactive dye wastewater, Environmental Engineering and Management Journal, 10, 1703-1709.

Dermentzis K., Valsamidou E. and Lazaridou A. (2011), Nickel removal from wastewater by electrocoagulation with aluminum electrodes, Journal of Engineering Science and Technology Review, 4, 188-192.

Dogan D. and Turkdemir H. (2005), Electrochemical oxidation of textile dye indigo, Journal of Chemical Technology and Biotechnology, 80, 916-923.

El-Desoky H.S., Ghoneim M.M., El-Sheikh R. and Zidan N.M. (2010), Oxidation of Lewafix CA reactive azo-dyes in industrial wastewater of textile dyeing by electro-generated Fenton's reagent, Journal of Hazardous Materials, 175, 858-65.

Flox C., Ammar S., Arias C., Brillas E., Vargas-Zavala A.V. and Abdelhedi R. (2006), Electro-Fenton degradation of indigo carmine in acidic aqueous medium, Applied Catalysis B: Environmental, 67, 93-104.

Hammami S., Oturan M.A., Oturan N., Bellakhal N. and Dachraoui M. (2012), Comparative mineralization of textile dye indigo carmine by photo-Fenton process and anodic oxidation using boron-doped diamond anode, Desalination and Water Treatment, 45, 297-304.

Kabdasli I., Vardar B., Arslan-Alaton I. and Tünay O. (2009), Effect of dye auxiliaries on color and COD removal from simulated reactive dye bath effluent by electrocoagulation, Chemical Engineering Journal, 148, 89-96.

Körbahti B.K., Artut K., Gecgel C.and Öyer A. (2011), Electrochemical decolorization of textile dyes and removal of metal ions from textile dye and metal binary mixtures, Chemical Engineering Journal, 173, 677-688.

Koshla N.K., Venkachalam S. and Sonrasundaram P. (1991), Pulsed electrogeneration of bubbles for electroflotation, Journal of Applied Electrochemistry, 21, 986-990.

Kyzas G. Z, Lazaridis N.K. and Mitropoulos A.Ch. (2012), Optimization of Batch Conditions and Application to FixedBed Columns for a Sequential Technique of Total Color Removal Using "Greek Coffee" Residues as Materials for Real Dyeing Effluents, Journal of Engineering Science and Technology Review, 5, 66-75.

Mollah M.Y.A., Pathak S.R., Patil P.K., Vayuvegula M., Agrawal T.S., Gomes J.A.G., Kesmez M. and Cocke D.I. (2009), Treatment of olive mill wastewater by the combination of ultrafiltration and bipolar electrochemical reactor processes, Journal of Hazardous Materials, B109, 165-171.

Motoc S., Manea F., Pop A., Baciu A., Burtica G. and Pode R. (2012), Electrochemical mineralization of reactive red 147 dye on boron-doped diamond electrodes, Environmental Engineering and Management Journal, 12, 509-516. 
Oturan M.A. and Brillas E. (2007), Electrochemical Advanced Oxidation Processes (EAOPs) for Environmental Applications, Portugaliae Electrochimica Acta, 25, 1-18.

Secula M.S., Cretescu I. and Petrescu S. (2011), An experimental study of indigo carmine removal from aqueous solution by electrocoagulation, Desalination 277, 227-235.

Vlyssides A.G., Loizidou M., Karlis P.K., Zorbas A.A. and Papaioannou D. (1999), Electrochemical oxidation of a textile dye wastewater using a Pt/Ti electrode, Journal of Hazardous Materials, B70, 41-52.

Wang C-T., Chou W-L., Chung M-H. and KuoY-M. (2010), COD removal from real dyeing wastewater by electroFenton technology using an activated carbon fiber cathode, Desalination, 253, 129-34.

Yatmaz H.C. and Uzman Y. (2009), Degradation of Pesticide Monochrotophos from Aqueous Solutions by Electrochemical Methods, Intern. J. Electrochem. Sci, 4, 614-26. 